\title{
Regulating health claims on food labels using nutrient profiling: what will the proposed standard mean in the Australian supermarket?
}

\author{
Clare Hughes ${ }^{1}$, Lyndal Wellard ${ }^{1, *}$, Jing Lin ${ }^{2}$, Ka Lun Suen ${ }^{2}$ and Kathy Chapman ${ }^{1}$ \\ 'Cancer Council NSW, 153 Dowling Street, Sydney, NSW 2011, Australia: ${ }^{2}$ School of Molecular Bioscience, \\ University of Sydney, Sydney, Australia
}

Submitted 13 August 2012: Final revision received 30 0ctober 2012: Accepted 16 November 2012: First published online 11 January 2013

\begin{abstract}
Objective: Proposed Australian regulation of claims on food labels includes requirements for products carrying a health claim to meet nutrient profiling criteria. This would not apply to nutrition content claims. The present study investigated the number and healthiness of products carrying claims and the impact of the proposed regulation.

Design: Observational survey of claims on food packages across three categories: non-alcoholic beverages, breakfast cereals and cereal bars. Nutrient profiling was applied to products carrying claims to determine their eligibility to carry health claims under the proposed regulation.

Setting: Three large metropolitan stores from the three major supermarket chains in Sydney, Australia were surveyed in August 2011.

Subjects: All claims on 1028 products were recorded. Nutrition composition and ingredients were collected from the packaging, enabling nutrient profiling. The proportion of products in each category carrying claims and the proportion of these that did not meet the nutrient profiling criteria were calculated.

Results: Two-thirds of products in the three categories (ranging from 18 to $78 \%$ ) carried at least one claim. Of those carrying health claims, $31 \%$ did not meet the nutrient profiling criteria. These would be ineligible to carry these claims under the proposed regulation. Additionally, $29 \%$ of products carrying nutrition content claims did not meet the nutrient profiling criteria.

Conclusions: The number of products carrying nutrition content claims that did not meet the nutrient profiling criteria suggests that comprehensive regulation is warranted. Promotion of unhealthy foods using claims is potentially misleading for consumers and hinders their ability to select healthier foods. Implementation of the proposed regulation represents an improvement to current practice.
\end{abstract}

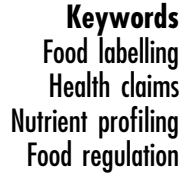

The provision of nutrition information on food labels can assist consumers to compare the nutritional value of food products and help them to make healthier food choices $^{(1)}$. In Australia, nutrition information that may appear on food labels includes the mandatory nutrition information panel, as well as optional health claims and nutrition content claims. Nutrition content claims are defined as statements about the presence or absence of a particular nutrient, such as 'source of calcium'(2). Health claims are statements about a nutrient in the food and its associated health benefit, such as 'calcium for healthy bones $^{,(2)}$. High level health claims are those relating to serious diseases (such as 'a healthy diet high in calcium may reduce the risk of osteoporosis') ${ }^{(2)}$.

Both health and nutrition content claims are used by food companies as marketing tools ${ }^{(2)}$. It has long been established that health claims are an effective way of increasing the sales of certain types of food over others in the same food category, such as high-fibre cereals over lower-fibre cereals ${ }^{(3,4)}$. Additionally, health claims have been shown to increase the market share of products carrying them immediately after the claims were introduced on to labels ${ }^{(3)}$. Therefore claims have the potential to influence consumer behaviour.

Products that carry claims may be perceived by consumers as healthier than those that do not carry claims $^{(5,6)}$. Previous research has shown that many products carrying or being advertised using claims are non-core foods, such as high-sugar/low-fibre breakfast cereals, chocolates, confectionery, cakes, biscuits, sports and energy drinks ${ }^{(7,8)}$. The public may also be easily confused about the nutritional profile of products carrying nutrition content claims ${ }^{(9)}$ and may misinterpret health and nutrition content claims, especially when scientific language is used 
in the claims ${ }^{(10)}$. Although the 'health halo' of unhealthy products carrying claims can be mediated by the presence of a nutrition information panel ${ }^{(11)}$, research has shown that many consumers either do not routinely use the nutrition information panel or are unable to correctly interpret it ${ }^{(9,12,13)}$. Therefore protecting consumers from claims on unhealthy products should be a priority for food regulators.

The food regulator, Food Standards Australia New Zealand (FSANZ), is responsible for developing food labelling standards in Australia and New Zealand ${ }^{(14)}$. Under the Food Standards Code (hereafter referred to as 'the Code'), health claims relating to serious diseases are currently prohibited, with the exception of claims on maternal folate consumption and a reduced risk of fetal neural tube defects ${ }^{(14,15)}$.

Presently, only high level health claims and nutrition content claims relating to the fatty acid profile of the food are regulated by the Code ${ }^{(14)}$. Other claims are governed by industry self-regulation. In 1995, a self-regulatory code of practice on the use of nutrition content claims was established, known as the Code of Practice on Nutrient Claims $^{(16)}$. Previous research has shown that this selfregulatory code is often not adhered to or enforced ${ }^{(17)}$. The limitations of the current regulatory approach, such as the difficulties in enforcing a voluntary code, have been noted by FSANZ and has led FSANZ to propose that nutrition content claims be regulated within the $\operatorname{Code}^{(2)}$.

Considering these limitations, in 2003 the state and national health ministers in Australia directed FSANZ to develop a standard to regulate nutrition content, health and related claims on food labels ${ }^{(2)}$. It has been proposed that claims on food labels would be regulated more strictly as the degree of promise increases ${ }^{(18)}$. The degree of promise is the potential benefit to the consumer in choosing that food in preference to others ${ }^{(18)}$. Under the proposed standard, products carrying nutrition content claims would have to meet minimum qualifying and disqualifying criteria relating to the claimed nutrient, and products carrying health claims would be required to meet nutrient profiling criteria in addition to the qualifying criteria, ensuring that only healthier products would be eligible to carry health claims ${ }^{(2)}$. Health claims relating to serious diseases (such as CVD) and biomarkers of serious diseases (such as blood cholesterol) would also need to be pre-approved by FSANZ and only on the basis of substantive evidence of the benefit claimed $^{(2)}$.

Nutrient profiling is a tool that assesses the overall healthiness of food products based on the energy and nutrient composition of the food ${ }^{(19)}$. The nutrient profiling system proposed by FSANZ is based on the UK Food Standards Agency's Nutrient Profiling Model, developed to assess which foods are healthy enough to be advertised to children ${ }^{(20)}$. The Australian nutrient profiling system has been designed specifically for determining a food's eligibility for health claims ${ }^{(21)}$. The system assigns points based on negative nutrients, such as energy, saturated fat, sodium and sugar content of foods, and deducts points based on positive nutrients such as protein and dietary fibre as well as the content of fruit, vegetables, nuts and legumes ${ }^{(22)}$. The lower the nutrient profiling score, the healthier the product is considered ${ }^{(21)}$. This model has been tested on over 10000 Australian and New Zealand food and beverage products ${ }^{(21)}$.

In January 2011 an independent panel commissioned to review food labelling law in Australia recommended extending the proposed standard to ensure that foods carrying any type of claim, including nutrition content claims, complied with this nutrient profiling system ${ }^{(23)}$. Although the Australian government supported the finalisation of the draft standard, the recommendation on using nutrient profiling for assessing eligibility for nutrition content claims was not supported ${ }^{(24)}$. Currently FSANZ is in the final stages of developing the standard and has conducted consultations on the way that health claims are substantiated, including investigating selfsubstantiation of health claims by the food industry as opposed to independent pre-market assessment of claims $^{(25)}$. Due to the quality of evidence required for scientific substantiation of health claims, many links between nutrients and health benefits may not be able to be appropriately substantiated and therefore unsubstantiated claims may appear on food labels if this approach was $\operatorname{adopted}^{(8)}$.

At present, there is no published evidence available on the impact of implementing the proposed standard on the food products that already carry claims. The present study aimed to address this research gap by investigating the healthiness of food products carrying health and nutrition content claims using the FSANZ nutrient profiling system. This will provide evidence of the potential impact of FSANZ's proposed regulation of claims.

\section{Experimental methods}

A survey of three food categories - non-alcoholic beverages, breakfast cereals and cereal bars - in Australian supermarkets was conducted to determine the number of products carrying health and nutrition content claims. These three categories were selected based on previous Australian research that suggested products in these categories frequently carry a range of health and/or nutrition content claims ${ }^{(8)}$.

\section{Procedures}

All available food products $(n$ 1028) in the non-alcoholic beverages, breakfast cereals and cereal bars categories were included. A description of these categories can be found in Table 1. 
Table 1 Description of the food categories surveyed

\begin{tabular}{|c|c|}
\hline Food category & Description \\
\hline $\begin{array}{c}\text { Non-alcoholic } \\
\text { beverages }\end{array}$ & $\begin{array}{l}\text { Fruit and vegetable juices } \\
\text { Sugar or artificially sweetened soft drinks } \\
\text { Energy drinks } \\
\text { Cordials } \\
\text { Sports electrolyte drinks } \\
\text { Flavoured still and sparkling water } \\
\text { Plain still and sparkling water }\end{array}$ \\
\hline Breakfast cereals & $\begin{array}{l}\text { Ready-to-eat breakfast cereals } \\
\text { Oats and other breakfast cereals that require } \\
\text { heating }\end{array}$ \\
\hline Cereal bars & $\begin{array}{l}\text { Plain cereal, muesli and nut-based bars } \\
\text { Chocolate-topped cereal, muesli and } \\
\text { nut-based bars } \\
\text { Yoghurt-toped cereal, muesli and nut-based } \\
\text { bars } \\
\text { Fruit-filled cereal bars }\end{array}$ \\
\hline
\end{tabular}

Data were collected in August 2011 by photographing all available product labels at three large metropolitan stores from the three major supermarket chains in Sydney, New South Wales. These stores were chosen to ensure that the largest number of products possible was included. For products that had multiple pack sizes, only the largest pack size was chosen for data analysis as a greater number of claims were likely to be displayed on a larger package. Each product was only recorded once, even when it was available at multiple supermarkets. All claims present on packages were recorded verbatim.

Data were collected on the nutrition composition (energy, protein, saturated fat, total sugar, sodium and dietary fibre content) from the nutrition information panel and the percentage of fruit, vegetables, nuts or legumes in the products from the ingredient list (as appropriate). Products were assessed using nutrient profiling. As it is not mandatory for manufacturers to list the dietary fibre content on the label, manufacturers were contacted to provide the dietary fibre content when it was not listed on the label. Where the manufacturer could not provide the dietary fibre content (as occurred for nine products), it was estimated from a comparable product.

When the percentage of any fruit, vegetable, nut or legume was not included in the ingredients list, it was estimated based on the ingredient order. This was possible because ingredients must be listed in descending order by weight, and the percentage contribution of characterising ingredients must be shown. Products must contain at least $40 \%$ fruit, vegetables, nuts or legumes to earn nutrient profiling modifying points; so for products where the percentage was unknown, nutrient profiling was done using 30\%, $40 \%$ and $50 \%$ fruit, vegetables, nuts and legumes content to determine whether it affected the nutrient profiling score. For the small number of products where the fruit, vegetables, nuts and legumes content affected the final nutrient profiling score, manufacturers were contacted to obtain the missing data.

\section{Types of claims}

All nutrition content, health and related claims on packaging were categorised systematically based on the nutrients, substances or health benefits that the claims referred to, using the Claims Classification Framework proposed by FSANZ ${ }^{(26)}$. Currently, wholegrain content claims are not covered by the Code. For the present research they have been included in the nutrition content claims category, because of their extensive use on breakfast cereal and cereal bar packaging, as well as claims promoting the benefits of dietary fibre.

'High level' health claims relating to serious diseases or biomarkers of serious diseases were also recorded. The definition of serious disease as adopted by FSANZ is any condition that cannot be diagnosed or treated safely without a qualified health-care professional ${ }^{(26)}$. Biomarkers are defined as a biological parameter that predicts the risk of serious diseases ${ }^{(26)}$.

\section{Nutrient profiling}

Products carrying claims were assessed using the FSANZ nutrient profiling scoring criteria, described above ${ }^{(22)}$. The standard FSANZ procedure was followed ${ }^{(26)}$. A product was classified as 'healthy' if it met the nutrient profiling criteria and was therefore eligible to make a health claim under the proposed regulation. All other products were classified as 'unhealthy'.

\section{Reliability}

All photographs were cross-checked by two different researchers (J.L. and K.L.S.), then all claim wordings and classifications were checked by another researcher (L.W.) to ensure that results were reliable.

\section{Analyses}

All data were entered into a Microsoft ${ }^{\circledR}$ Excel 2007 database. Descriptive analyses were conducted to determine the proportion of products carrying claims overall and for each of the three food categories. The proportion of products carrying claims that were classified as unhealthy when nutrient profiling was applied was calculated for all products and each food category. The number and proportion of products carrying high level health claims were also determined for each category.

\section{Results}

\section{Sample size and total number of claims}

Overall, 1028 products were identified across the three food categories. This included 598 non-alcoholic beverages, 264 breakfast cereals and 166 cereal bars. Overall, $67 \%$ of products ( $n$ 684) carried at least one claim. Most products carried only nutrition content claims (49\%, $n$ 500); however, some carried both nutrition content and health claims $(17 \%, n 171)$, and a smaller number carried only health claims $(1 \%, n 13)$. 


\section{Proportion of all products that carried claims}

The proportion of all products that carried claims varied between categories, from $56 \%$ ( $n$ 335) in non-alcoholic beverages to $84 \%$ ( $n$ 221) in breakfast cereals. A smaller proportion of all products carried health claims (18\%, $n$ 184), ranging from $10 \%$ of non-alcoholic beverages ( $n$ 60) to $38 \%$ of breakfast cereals ( $n 101$ ). Many products carried nutrition content claims $(65 \%, n$ 671), ranging from $54 \%$ of non-alcoholic beverages ( $n$ 324) to $83 \%$ of breakfast cereals ( $n$ 219). Table 2 shows the number and proportion of total products carrying claims.

\section{Proportion of all products in each category that carried claims and did not meet the nutrient profiling criteria}

In each of the three categories, only a small proportion of products that carried health claims were rated as unhealthy. This included $4 \%$ of non-alcoholic beverages ( $n$ 21), $7 \%$ of breakfast cereals ( $n$ 18) and $11 \%$ of cereal bars ( $n$ 18). A higher proportion of products carrying nutrition content claims were rated as unhealthy. This included $9 \%$ of all non-alcoholic beverages ( $n 54), 14 \%$ of all breakfast cereals ( $n$ 37) and $61 \%$ of all cereal bars ( $n$ 101).

\section{Proportion of products carrying claims that did not meet the nutrient profiling criteria}

When focusing only on the products carrying claims, $30 \%$ of products carrying any claim ( $n$ 204), $31 \%$ of products carrying health claims ( $n$ 57) and 29\% of products carrying nutrition content claims ( $n$ 192) did not meet the nutrient profiling criteria. Cereal bars had the highest proportion of unhealthy products carrying health claims (78\%, $n$ 18) and nutrition content claims (79\%, $n$ 101), while breakfast cereals had the lowest (18\%, $n 18$ and $17 \%, n 37$ for health and nutrition content claims respectively). The proportion of products carrying claims that failed nutrient profiling is shown in Table 3.

\section{Types of claims}

Many products carried a variety of nutrition content and/or health claims, and some carried the same claims multiple times. Overall, there were 3721 total claims recorded across the three product categories, including 530 health claims and 3191 nutrition content claims. Of these claims, thirty-seven different types of health claims and fifty different nutrition content claims were identified.

The types of claims occurring most frequently varied between the categories. For non-alcoholic beverages, low sugar content/no added sugar ( $n$ 310) and physical performance ( $n 35$; e.g. 'carbohydrates and electrolytes... to help you perform at your peak for longer') were the most common nutrition content and health claims, respectively. For cereal bars, dietary fibre content ( $n$ 134) and general well-being claims ( $n$ 18; e.g. 'nutrients to help maintain your family's wellbeing') were the most common nutrition content and health claims, respectively. For breakfast cereals, wholegrain content $(n$ 477) and energy/vitality claims ( $n$ 87; e.g. 'real fruit... to provide everyday vitality') were the most common nutrition content and health claims, respectively. Other common nutrition content claims across the three categories were for vitamin $\mathrm{C}$ content, low fat content and low energy content. Other common health claims included digestion

Table 2 Proportion of all products carrying claims in three large metropolitan stores from the three major supermarket chains in Sydney, Australia in August 2011

\begin{tabular}{|c|c|c|c|c|c|c|}
\hline \multirow[b]{2}{*}{ Food category } & \multicolumn{2}{|c|}{ Any claim* } & \multicolumn{2}{|c|}{ Health claims } & \multicolumn{2}{|c|}{ Nutrition content claims } \\
\hline & $\%$ & $n$ & $\%$ & $n$ & $\%$ & $n$ \\
\hline Non-alcoholic beverages ( $n$ 598) & 56 & 335 & 10 & 60 & 54 & 324 \\
\hline Breakfast cereals ( $n$ 264) & 84 & 221 & 38 & 101 & 83 & 219 \\
\hline Cereal bars ( $n$ 166) & 77 & 128 & 14 & 23 & 77 & 128 \\
\hline Total $(n$ 1028) & 67 & 684 & 18 & 184 & 65 & 671 \\
\hline
\end{tabular}

*Some products carried both health and nutrition content claims.

Table 3 Proportion of products carrying claims that did not meet the nutrient profiling criteria in three large metropolitan stores from the three major supermarket chains in Sydney, Australia in August 2011

\begin{tabular}{|c|c|c|c|c|c|c|c|c|c|}
\hline \multirow[b]{3}{*}{ Food category } & \multicolumn{3}{|c|}{ Any claims* } & \multicolumn{3}{|c|}{ Health claims } & \multicolumn{3}{|c|}{ Nutrition content claims } \\
\hline & \multirow[b]{2}{*}{ Number } & \multicolumn{2}{|c|}{ Did not meet criteria } & \multirow[b]{2}{*}{ Number } & \multicolumn{2}{|c|}{ Did not meet criteria } & \multirow[b]{2}{*}{ Number } & \multicolumn{2}{|c|}{ Did not meet criteria } \\
\hline & & $\%$ & $n$ & & $\%$ & $n$ & & $\%$ & $n$ \\
\hline Non-alcoholic beverages & 335 & 20 & 66 & 60 & 35 & 21 & 324 & 17 & 54 \\
\hline Breakfast cereals & 221 & 17 & 37 & 101 & 18 & 18 & 219 & 17 & 37 \\
\hline Cereal bars & 128 & 79 & 101 & 23 & 78 & 18 & 128 & 79 & 101 \\
\hline Total & 684 & 30 & 204 & 184 & 31 & 57 & 671 & 29 & 192 \\
\hline
\end{tabular}

*Some products carried both health and nutrition content claims. 
(e.g. 'high in fibre for healthy digestion'), performance (e.g. 'low GI... to keep your body active and achieve your goals') and hydration (e.g. 'electrolytes and carbohydrates to provide faster hydration').

\section{High level bealth claims}

A total of twenty-three products $(2 \cdot 2 \%$ of all products) carried high level health claims regarding serious diseases and/or biomarkers of serious diseases. The majority of these ( $n$ 20) were claims on reducing cholesterol; the others related to preventing cancer, reducing blood pressure and improving inflammation in arthritis and gout. Of the twenty-three products carrying high level health claims, three did not meet the nutrient profiling criteria.

\section{Discussion}

The present study found that a large proportion of products in the non-alcoholic beverage (56\%), breakfast cereal (84\%) and cereal bar (77\%) categories in Australia carried at least one type of claim on their label. These results are slightly higher than an Australian survey conducted in 2006, which found that $55 \%$ of non-alcoholic beverages and $69 \%$ of cereal products (which included breakfast cereals, cereal bars and other subcategories) carried claims ${ }^{(27)}$. The number of packages carrying claims is likely to be higher if multiple pack sizes had been included in the analysis.

The food industry has stated that the introduction of the proposed standard may have significant costs for package redesign and reformulation of products that would no longer comply if the proposed regulation was implemented $^{(28)}$. The present study found that the total number of unhealthy products that currently carry health claims is low, and these account for no more than $11 \%$ of all products assessed in the study. Therefore the burden of implementing the proposed regulation for health claims on the food industry would be minimal, especially as packages are regularly redesigned and the lead time for introducing new regulation is likely to be long. The implementation of the proposed regulation would be an improvement on current labelling practice given the implications to public health, including ensuring consumers are not misled and enabling healthier food choices.

The study showed that although there was a high proportion of unhealthy cereal bars that carried nutrition content claims (79\%), the other two categories had much lower proportions (both 17\%). Under the proposed regulation, nutrient profiling would not be applied to nutrition content claims and products could carry nutrition content claims even if they did not meet the nutrient profiling criteria. The presence of nutrition content claims therefore does not guarantee that the product is a healthy choice.
There was a range of health claims identified in the present study. While some claims, such as fibre for digestive health, are being considered for pre-approval by FSANZ as there is sufficient evidence of their benefit ${ }^{(29)}$, other claims found, such as low GI to improve performance, may not have sufficient evidence to allow them to be made. The range of claims found in the study provides evidence of the need for pre-market approval of claims in the proposed regulation.

Promoting a particular nutrition content claim (such as high calcium content) and remaining silent on the less beneficial nutritional attributes (for example high saturated fat content or high added sugar content) is a common practice used to market products ${ }^{(30)}$. Although the nutrition information panel provides information on the energy and some aspects of a product's nutrient composition, it is difficult for consumers to judge the overall nutritional values of products from packaging and claims alone ${ }^{(30)}$. Consumers may be unable to distinguish between nutrition content claims and health claims, and may attribute a health benefit to a product carrying a nutrition content claim, especially if they are aware of any nutrient-disease relationships associated with that nutrient ${ }^{(2,5,31,32)}$. For example, participants in one study believed that a product carrying a heart-healthy claim actually protected against heart disease and stroke ${ }^{(11)}$, while another study found that very few consumers could correctly interpret various health claims, such as "no added sugar'(33). Consumers may also assume that a product carrying a nutrition content claim is healthy on the basis that it carries a claim, or deliberately seek and purchase foods carrying claims for this reason ${ }^{(32,34)}$. This may lead them to choose and consume such foods thinking they are healthy when that may not be the case ${ }^{(30,35)}$, which is potentially misleading. Unhealthy products carrying nutrition content claims could be at risk of breaching the Australian Competition and Consumer Regulations 2010, which state that people or businesses must not engage in conduct that is misleading or deceptive or is likely to mislead or deceive ${ }^{(36)}$.

As well as ensuring that unhealthy products do not carry nutrition content claims, applying nutrient profiling to assess the eligibility of products to carry claims may motivate food companies to develop healthier products or reformulate their existing products so they could carry a claim ${ }^{(37,38)}$, which in turn may improve the nutritional status of the population ${ }^{(39)}$. The food industry has expressed concern that the proposed regulation may stifle innovation $^{(28)}$. This is counterintuitive, as industry is likely to respond to regulations by developing new products and reformulating existing products to achieve nutrition benchmarks set by the regulations.

Although high level health claims are currently prohibited under the Code, biomarker claims such as reducing cholesterol are not presently considered high level claims. Under the draft standard, biomarkers would 
be considered high level health claims ${ }^{(2)}$, and several products carrying these types of claims identified in the present study would not be permitted to continue doing so. While the proportion of products carrying high level health claims was low, it was higher than in previous research in Australia $(1 \cdot 2 \%)^{(8)}$. If food companies do not comply with law, they are unlikely to comply with voluntary codes of practice, hence providing more evidence for the need for government regulation and monitoring for all types of claims.

In the absence of consistent regulation of all types of claims, an interpretive front-of-pack labelling scheme may mediate confusion caused by nutrition content claims on unhealthy food products ${ }^{(23)}$. The introduction of a multiple traffic light front-of-pack system was recommended by the independent panel in the food labelling review ${ }^{(23)}$ and has been supported by recent research ${ }^{(40-43)}$. The present study provides more rationale for the introduction of interpretive front-of-pack labelling.

A limitation of the study was that only three food categories were assessed, so the study is not representative of all types of food in Australian supermarkets. However these three categories were chosen because products in them were likely to carry many claims. The research should be repeated in other food categories to provide a broader overview of the number and types of claims across the supermarket.

Large outlets of the three major supermarket chains were surveyed, including the two biggest chains (which account for $>70 \%$ of the grocery market share) ${ }^{(44)}$ and the largest independent supermarket. This would have captured the majority of the products available in these categories in Australia, although it is possible that not all products available in the three food categories were included in the data collection, especially if smaller, independent supermarkets and stores stock specific brands exclusively.

The lack of standard definitions for the interpretation and classification of claims is also a limitation. For example, it was difficult to classify nutrition content claims referring generally to 'micronutrients' or health claims about 'detoxification'. The definitions and descriptions of the different types of claims in the proposed regulation are not sufficiently detailed to account for the complexity of actual claims presented on food products. However, effort was taken to ensure the claims were classified systematically and data were checked twice for consistency of interpretation.

\section{Conclusion}

The present study was the first to investigate the eligibility of food products to carry health claims using nutrient profiling in Australia, and provides evidence to support the recommendations of public health and independent experts for a more comprehensive regulatory approach.
Overall, a large proportion of the food products surveyed carried some sort of health or nutrition content claim. Of the products carrying health claims, $31 \%$ did not meet the nutrient profiling criteria and would be ineligible to carry health claims if the proposed regulation is implemented. This was a small proportion of the total food products in each category surveyed (between $4 \%$ of breakfast cereals and $11 \%$ of cereal bars). Our research shows that the regulation is unlikely to place a prohibitively large burden on the food industry, although it will be more marked in some food categories. The study highlights that consumers may be more likely to be misled by health claims on unhealthy products in some food categories than others, should the proposed regulation not be implemented. The implementation of the proposed regulation preventing health claims on unhealthy foods will be an improvement on current labelling practice and may assist consumers in choosing healthier products.

Although 29\% of products carrying nutrition content claims did not meet the nutrient profiling criteria, they would still be able to carry these claims under the proposed regulations. By allowing unhealthy products to carry nutrition content claims, consumers may be led to believe that these unhealthy products are healthy. To assist the public to make healthy choices and prevent them being misled by nutrition content claims on unhealthy products, government should implement consistent regulation for all types of claims on food labels. Further, implementation of an interpretive front-of-pack labelling system may mediate any confusion caused by claims on food labels.

If the proposed regulation is adopted, consumer education will be needed to ensure the public is able to correctly interpret the nutrition information, including definitions on the types of claims and differences between health and nutrition content claims. This is particularly important if nutrition content claims continue to be allowed on unhealthy foods, as the public may regard these products as healthy, based on the fact that they carry a claim.

\section{Acknowledgements}

Sources of funding: The study was funded by Cancer Council NSW. Conflicts of interest: There are no conflicts of interest to declare. Ethics: Ethical approval was not required. Authors' contributions: C.H. conceived the study, supervised the data collection and contributed substantially to the manuscript. L.W. supervised the data collection, checked the data, conducted the final analyses and prepared the manuscript. J.L. and K.L.S. conducted data collection, checked the data, conducted and interpreted the preliminary analyses and contributed to the manuscript. K.C. contributed substantially to the manuscript. Acknowledgements: The authors thank Rosemary Stanton and Bridget Kelly for their feedback on the draft manuscript. 


\section{References}

1. Cowburn G \& Stockley L (2005) Consumer understanding and use of nutrition labelling: a systematic review. Public Health Nutr 8, 21-28.

2. Food Standards Australia New Zealand (2008) Final Assessment Report for Proposal P293 - Nutrition, Health and Related Claims. Consumer research supporting the development of the draft Standard. http://www.foodstandards.gov.au/_srcfiles/ P293\%20Health\%20Claims\%20FAR\%20Attach\%2010\%20 FINAL.doc (accessed February 2009).

3. Levy AS \& Stokes RC (1987) Effects of a health promotion advertising campaign on sales of ready-to-eat cereals. Public Health Rep 102, 398-403.

4. Ippolito PM \& Mathios AD (1991) Health claims in food marketing: evidence on knowledge and behavior in the cereal market. J Public Policy Mark 10, 15-32.

5. Williams PG (2005) Consumer understanding and use of health claims for foods. Nutr Rev $\mathbf{6 3}, 256-264$.

6. Dixon H, Scully M, Wakefield M et al. (2011) Parent's responses to nutrient claims and sports celebrity endorsements on energy-dense and nutrient-poor foods: an experimental study. Public Health Nutr 14, 1071-1079.

7. Kelly B, Hattersley L, King L et al. (2009) Smoke and mirrors: nutrition content claims used to market unhealthy food. Nutr Diet 66, 62-64.

8. Williams P, Yeatman H, Ridges L et al. (2006) Nutrition function, health and related claims on packaged Australian food products - prevalence and compliance with regulations. Asia Pac J Clin Nutr 15, 10-20.

9. Food Standards Australia New Zealand (2003) A Qualitative Consumer Study Related to Nutrition Content Claims on Food Labels. Canberra: FSANZ.

10. Mariotti F, Kalonji E, Huneau JF et al. (2010) Potential pitfalls of health claims from a public health nutrition perspective. Nutr Rev 68, 624-638.

11. Kozup JC, Creyer EH \& Burton S (2003) Making healthful food choices: the influence of health claims and nutrition information on consumers' evaluations of packaged food products and restaurant menu items. J Mark 67, 19-34.

12. Jones G \& Richardson M (2007) An objective examination of consumer perception of nutrition information based on healthiness ratings and eye movements. Public Health Nutr 10, 238-244.

13. Ni Mhurchu C \& Gorton D (2007) Nutrition labels and claims in New Zealand and Australia: a review of use and understanding. Aust N Z J Public Health 31, 105-112.

14. Food Standards Australia New Zealand (2009) Australia New Zealand Food Standards Code. http://www. foodstandards.gov.au/foodstandards/foodstandardscode.cfm (accessed October 2012).

15. Food Standards Australia New Zealand (2008) Standard 1.1A.2 Transitional Standard - Health Claims. http:// www.comlaw.gov.au/Series/F2008B00802 (accessed May 2011).

16. Australia New Zealand Food Authority (1995) Code of Practice Nutrient Claims in Food Labels and in Advertisements. Canberra: ANZFA.

17. Williams P, Yeatman H, Zakrzewski S et al. (2003) Nutrition and related claims used on packaged Australian foods implications for regulation. Asia Pac J Clin Nutr 12, 138-150.

18. Australia New Zealand Food Regulation Ministerial Council (2012) Policy Guideline on Nutrition, Health and Related Claims. http://www.health.gov.au/internet/main/publishing. nsf/Content/00E8A0712A1A5C3BCA2578A7007FBE77/\$File/ nutrition_guidelines.pdf (accessed March 2012).

19. Scarborough P, Rayner M \& Stockley L (2007) Developing nutrient profile models: a systematic approach. Public Health Nutr 10, 330-336.
20. Rayner M, Scarborough P \& Lobstein T (2009) The UK Ofcom Nutrient Profiling Model: Defining 'Healthy' and 'Unhealthy' foods and drinks for TV advertising to children. http://www.dph.ox.ac.uk/bhfhprg/publicationsandreports/ acad-publications/bhfhprgpublished/nutrientprofilemodel (accessed September 2012).

21. Food Standards Australia New Zealand (2007) Preliminary Final Assessment Report. Proposal P293 Nutrition, Health and Related Claims. Canberra: FSANZ.

22. Food Standards Australia New Zealand (2012) Calculation Method for Determining Foods Eligible to Make Health Claims. Health Claims Nutrient Profiling Calculator. http://www.foodstandards.gov.au/_srcfiles/method\%20to \%20determine\%20eligibility\%20_ final_.pdf (accessed May 2012).

23. Blewett N, Goddard N, Pettigrew S et al. (2011) Labelling Logic - the Final Report of the Review of Food Labelling Law and Policy. http://www.foodlabellingreview.gov.au/ internet/foodlabelling/publishing.nsf/content/labelling-logic (accessed August 2011).

24. Legislative and Governance Forum on Food Regulation (2011) Response to the Recommendations of Labelling Logic: Review of Food Labelling Law and Policy (2011). Canberra: Australia and New Zealand Food Regulation Ministerial Council.

25. Australian Government, Department of Health and Ageing (2012) Legislative and Governance Forum on Food Regulation Communiqué 20 July 2012. https://www.health.gov. $\mathrm{au} /$ internet/main/publishing.nsf/Content/foodsecretariatcommuniques.htm (accessed October 2012).

26. Food Standards Australia New Zealand (2004) Initial Assessment Report Proposal P293 Nutrition, Health and Related Claims. http://www.foodstandards.gov.au/_srcfiles/ Full_report_IARandattachments.pdf (accessed March 2012).

27. Food Standards Australia New Zealand (2007) On-going Food Label Monitoring Survey in Australia and New Zealand. Report on the Assessment of 2005 Labels for Nutrition, Health and Related Claims. Canberra: FSANZ.

28. Australian Food and Grocery Council (2012) Submission to Food Standards Australia New Zealand in Response to Proposal P293 - Nutrition, Health and Related Claims. Canberra: Australian Food and Grocery Council.

29. Food Standards Australia New Zealand (2012) Call for Submissions - Proposal P293 Nutrition Health and Related Claims. http://www.foodstandards.gov.au/_srcfiles/P293\%20 Nutrition_Health_related\%20claims\%20consult \%20paper1.pdf (accessed March 2012).

30. Harris JL, Thompson JM, Schwartz MB et al. (2011) Nutrition-related claims on children's cereals: what do they mean to parents and do they influence willingness to buy? Public Health Nutr 14, 2207-2212.

31. van Trijp HCM \& van der Lans IA (2007) Consumer perceptions of nutrition and health claims. Appetite $\mathbf{4 8}$, 305-324.

32. Lynam AM \& McKevitt A (2011) Irish consumers' use and perception of nutrition and health claims. Public Health Nutr 14, 2213-2219.

33. Food Standards Australia New Zealand (2003) Food Labelling Issues: Quantitative Research with Consumers. Evaluation Report Series no. 4. Canberra: FSANZ.

34. Food Standards Australia New Zealand (2005) Food Labelling Issues: Quantitative Research on Consumers' Perceptions and Use of Nutrition, Health and Related Claims on Packaged Foods. Canberra: FSANZ.

35. Food Standards Agency (2002) Health Claims on Food Packaging. Consumer-related Qualitative Research. London: FSA.

36. Australian Government (2010) Competition and Consumer Act 2010 (Cth). http://www.comlaw.gov.au/Details/C2012C00198/ Html/Volume_3\#_Toc316291776 (accessed February 2012). 
37. Drewnowski A (2007) An update on nutrient profiling in the European Union and the US: what's in store for nutrition labelling and health claims? Nutr Today $\mathbf{4 2}$, 206-214.

38. Centre for International Economics (2008) Nutrition, Health and Related Claims: A Benefit-Cost Analysis. Canberra: FSANZ.

39. van Raaij J, Hendriksen M \& Verhagen H (2009) Potential for improvement of population diet through reformulation of commonly eaten foods. Public Health Nutr 12, 325-330.

40. Kelly B, Hughes C, Chapman K et al. (2009) Consumer testing of the acceptability and effectiveness of front-ofpack food labelling systems for the Australian grocery market. Health Promot Int 24, 120-129.
41. Hieke S \& Wilczynski P (2012) Colour Me In - an empirical study on consumer responses to the traffic light signposting system in nutrition labelling. Public Health Nutr 15, 773-782.

42. McLean R, Hoek J \& Hedderley D (2012) Effects of alternative label formats on choice of high- and lowsodium products in a New Zealand population sample. Public Health Nutr 15, 783-791.

43. Roberto CA, Bragg MA, Seamans MJ et al. (2012) Evaluation of consumer understanding of different front-of-package nutrition labels, 2010-2011. Prev Chronic Dis 9, E149.

44. Australian Competition \& Consumer Commission (2008) Report of the ACCC Inquiry into the Competitiveness of Retail Prices for Standard Groceries. Canberra: ACCC. 